\title{
A geospatial approach for site suitability and accessibility for healthcare services in Bankura district, West Bengal, India
}

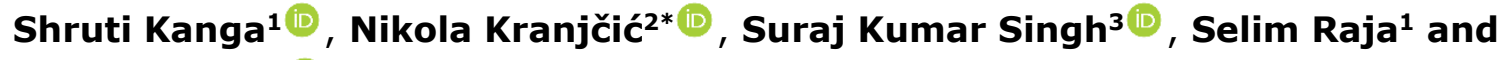 \\ Bojan Đurin 4
}

1 Centre for Climate Change and Water Research, Suresh Gyan Vihar University, Jaipur 302017, India; shruti.kanga@mygyanvihar.com

2 Faculty of Geotechnical Engineering, University of Zagreb, Hallerova aleja 7, 42000 Varaždin, Croatia; nikola.kranjcic@gfv.unizg.hr

3 Centre for Sustainable Development, Suresh Gyan Vihar University, Jaipur, 302017, India; suraj.kumar@mygyanvihar.com

4 Department of Civil Engineering, University North, 42000 Varaždin, Croatia, bojan.durin@unin.hr

* Correspondence: nikola.kranjcic@gfv.unizg.hr

Keywords: Healthcare accessibility, Site Suitability, TOPSIS, MCDA, GIS

\begin{abstract}
Healthcare site selection assumes an imperative part in healthcare development and management. From part of the public authority, proper medical site selection will help the distribution of clinical assets, coordinating with the arrangement of medical care with the social and economic demands, organizing the metropolitan and rural healthcare administration advancement, and facilitating social logical inconsistencies. Site suitability analysis is a variety of analysis utilized in GIS to work out the simplest place or site for one thing. The main objective of the current study was to select a site for new healthcare services with geospatial technologies to intermix spatial and non-spatial data to create a weighted result. The current study had been done into three phases, where many processes are intermixed into a single phase. In the first phase of analysis, distance, density, and proximity were mapped to seek out poor and lower accessible areas of healthcare from existing healthcare. To selecting new healthcare sites, four-factor criteria (Buffer around road and rail, land use land cover and buffer around settlement, ) and some constrain criteria considered in the second phase of analysis. Finally, the shortest network path analysis has been done in the third phase to determine the shortest and best route from selected healthcare sites towards district medical college. The current study presents some suitable sites in the poor and inaccessible areas of the district. This study will be very helpful for the decision support system of healthcare management in the future.
\end{abstract}

\section{Introduction}

"Good Health and Well-being", is one of the 17 Sustainable Development Goals established by the United Nations in 2015. The official wording is: "To ensure healthy lives and promote well-being for all at all ages."(Nations, 2015). These days Peoples are more healthcare cognizant due to carry on with in healthy life and that is encourage immense interest for healthcare services. HealthCare's are perhaps the most significant infrastructural objects. Healthcare's are typically subsidized by different public areas, by benefit or non-benefit healthcare associations, noble cause, insurance agencies or even strict orders. (Nghiem and Connelly, 2017) 
Healthcare site selection is identified with different parts of the public. Blended perspectives and discussions on which measures are most significant would confound even healthcare services specialists. Consequently, the choice cycle requires an interdisciplinary methodology including medical clinic the board staff, government authorities, engineers, natural and social researchers. GIS-based MCA technique with factor criteria during this study transfers all these qualitatively chosen criteria into quantitative analysis, creating the results a lot of convincing. The decision-makers reach in a deeper understanding of the structure of the problem with the help of selected criteria. As a matter of reality, there is not a precise and unified regulation on hospital site selection in the Bankura health department. Most of the decisions are subjectively and randomly relied on the government officials. This discretionary implicit standard has led to defilement, particularly for the site choice of private benefit emergency clinic. Subsequently, this investigation can be viewed as an illustration to give some logical and significant ideas to elevate the healthcare office to perfect the laws and guidelines on emergency healthcare site selection. The examination will delineate how spatial dynamic apparatuses, for example, GIS-based MCA can help chiefs in the healthcare services field.

The main objective of the present study is to establish a decision-making approach to select a suitable site for building a new hospital in Bankura district of West Bengal to the incorporation of spatial and non-spatial data with GIS to shape a weighted outcome. Considering various factor criteria, and The Technique for Order of Preference by Similarity to Ideal Solution (TOPSIS) are employed here for determining the best to worst site by arrange the rank of proposed sites. Also, this research included studies for the evaluation of accessibility, the selection of appropriate sites for healthcare facilities.

(Zhou and $\mathrm{Wu}, 2012$ ) in their investigations were utilized to choose a site for building another emergency clinic utilizing GIS-based Multi-Criteria Analysis (MCA). With Analytical Hierarchy Process (AHP) and Rank Order Method (ROM) for the weight setting on factor rules, need tests and affectability tests are applied to check which standards are truly vital and how the outcomes are touchy to their weight change. They presumed that GIS-based MCA with need and affectability tests proposes a novel and helpful reference to other site selection leaders, and furthermore gives productive devices to the policy implementation to set up effective data sets for chiefs to do spatial investigations.

(Abdullahi, Mahmud and Pradhan, 2014) site appropriateness displaying is a process measure including different sorts of targets and issues. A particularly mind-boggling measure incorporates spatial investigation, utilization of a few choice help devices like distantly detected information, geological data framework (GIS) and multi rules examination (MCA, for example, insightful pecking order measure (AHP), and sometimes, expectation strategies like cell automata (CA) or fake neural organizations (ANN). Their paper introduced an examination between the consequences of AHP and the standard least square (OLS) assessment model, in view of different rules, to choose appropriate destinations for new emergency clinics.

(Stylianidis, Roustanis and Karanikolas, 2009) in their investigation introduced a two phases procedure to assess the current areas of medical care offices in Thiruverumbur block, Tiruchirappalli region of Tamil Nadu, India and incorporates to distinguish the ideal site for new medical care office. First and foremost, they utilized Spatial Accessibility file to medical care offices which are estimated utilizing Three Step Floating Catchment Area (3SFCA) in a geospatial structure, thinking about three factors; to be specific, appeal of medical care offices, travel time or distance between the areas of the help place and the home, and populace interest for healthcare services offices. Also, the Multi-model's choice investigation has created to discover ideal locales for new healthcare services office in the denied territory. The investigation additionally incorporates street network examination, to decide the nearest office and most brief course to these healthcare 
services offices from the populace. The investigation was in this manner, suggested as a spatial choice emotionally supportive network for metropolitan approach creators with respect to availability of medical care offices in the metropolitan and rustic territory.

(Pan et al., 2018) in their paper, proposed a novel coordinated catchment region (ICA) that incorporates real human travel conduct to assess the openness to medical care offices in China, utilizing the improved two-venture skimming catchment territory (E2SFCA) strategy. Which is likewise called the E2SFCA-ICA technique. In the first place, access likelihood was proposed to portray the likelihood of visiting a medical care office. In this way, incorporated admittance likelihood (IAP), which coordinates model-based admittance likelihood (MAP) and information-based admittance likelihood (DAP), was introduced. At long last, the ICA and subzones were consolidated into the E2SFCA strategy to assess the openness of the top-level clinics.

(Ozturk and Batuk, 2011) are read on TOPSIS for Spatial Decision Problems. Theirs paper introduced an apparatus that incorporates GIS and TOPSIS strategy. The device has abilities, including basis normalization, model weighting and choice investigation with TOPSIS. The paper likewise introduced a utilization of GIS-based TOPSIS by applying the ArcGIS-TOPSIS instrument to a true issue that elaborate choice of settlement site. Since the strategies performed by ArcGIS, TOPSIS are nonexclusive, the apparatus can be utilized for some other choice applications, including normal asset the executives, land-use arranging and appropriateness assessment.

(Nyimbili, Erden and Karaman, 2018) are concentrated in Integration of GIS, AHP and TOPSIS for quake risk investigation. They utilized MCDA strategies of the Analytical Hierarchical Process (AHP) and the Technique for Order Preference by Similarity to Ideal Solution (TOPSIS), incorporated with GIS, were utilized to create tremor peril and hazard maps for quake debacle checking and examination for their space of revenue. AHP was utilized to decide the loads of measures boundaries, which were additionally utilized as contribution to the TOPSIS strategy and GIS (ESRI ArcGIS) for reproducing these yields to create tremor peril maps. The subsequent quake peril maps made by both the AHP and TOPSIS models were analyzed, showing high connection and similarity.

(Jozaghi et al., 2018) contribute their work for the Study of the AHP and TOPSIS Techniques for Dam Site Selection Using GIS. Their paper presents a relative investigation of TOPSIS and AHP with regards to multicriteria dynamic utilizing GIS for dam site determination. The examination was made dependent on geographic and water quality rules. The geological models are topography, land use, silt, disintegration, slant, groundwater, and release. The water quality models incorporate Soluble Sodium Percentage, Total Dissolved Solid, Potential of Hydrogen, and Electrical Conductivity of water. A proportion assessment system was utilized to decide the loads of these rules. The two strategies were applied for selection of ideal destinations for dams. The outcomes show that the TOPSIS technique is more qualified to the issue of dam site selection for this examination region. Genuine areas of dams developed in the space were utilized to confirm the consequences of the two techniques.

(Behzadian et al., 2012) concentrated on "A cutting edge study of TOPSIS applications". In this paper, they led a best in class writing overview to taxonomize the exploration on TOPSIS applications and procedures. The arrangement plot for this survey contains 266 academic papers from 103 diaries since the year 2000, isolated into nine application zones: (1) Supply Chain Management and Logistics, (2) Design, Engineering and Manufacturing Systems, (3) Business and Marketing Management, (4) Health, Safety and Environment Management, (5) Human Resources Management, (6) Energy Management, (7) Chemical Engineering, (8) Water Resources Management and (9) Other points. 
(Parvin et al., 2021) dealt with accessibility and site suitability for healthcare services in Murshidabad, India using GIS-based hybrid decision-making approach. (Mishra et al., 2019) used GIS and multi-criteria techniques with spatial weightage to define suitable locations for new health services in rural India. (Rekha et al., 2017) defined geospatial techniques such as 3SFCA, MCD and spatial decision support to define health care facility accessibility. (Pu et al., 2020) systemized the approach to evaluate spatial accessibility in resource poor regions such as Democratic Republic of Congo, to integrate spatial accessibility and location-allocation model for healthcare planning. (Zhao et al., 2018) used network big data to achieve sustainable urban communities with accessibility assessment for residential suitability. For West Bengal, (Dutta et al., 2021) provided spatial analysis and modelling to establish primary healthcare site selection. (Case, Hawthorne, 2013; Beheshtifar, Alimoahmmadi, 2015; Ahmad et al., 2020) also used geographical information systems to access suitability for health/social services in different countries.

\section{Study area and methodology}

Bankura is one of the twenty third district of West Bengal state in India. It is arranged between $22^{\circ} 38^{\prime}$ and $23^{\circ} 38^{\prime}$ north latitude and between $86^{\circ} 36^{\prime}$ and $87^{\circ} 46^{\prime}$ east longitude. On the north and north-east the district is limited by Bardhaman district, from which it is isolated by the Damodar River. On the south-east it is limited by Hooghly district, on the south by Paschim Medinipur district and on the west by Purulia district. It has a space of 6,788 square kilometers $(2,621 \mathrm{sq} \mathrm{mi})$ and stands firm on the second biggest foothold among the districts of the states as far as land region. Starting at 2011 enumeration, Bankura had a populace of 3596901 . This district has a normal education pace of 70.95 , higher than the public normal of $59.50 \%$.

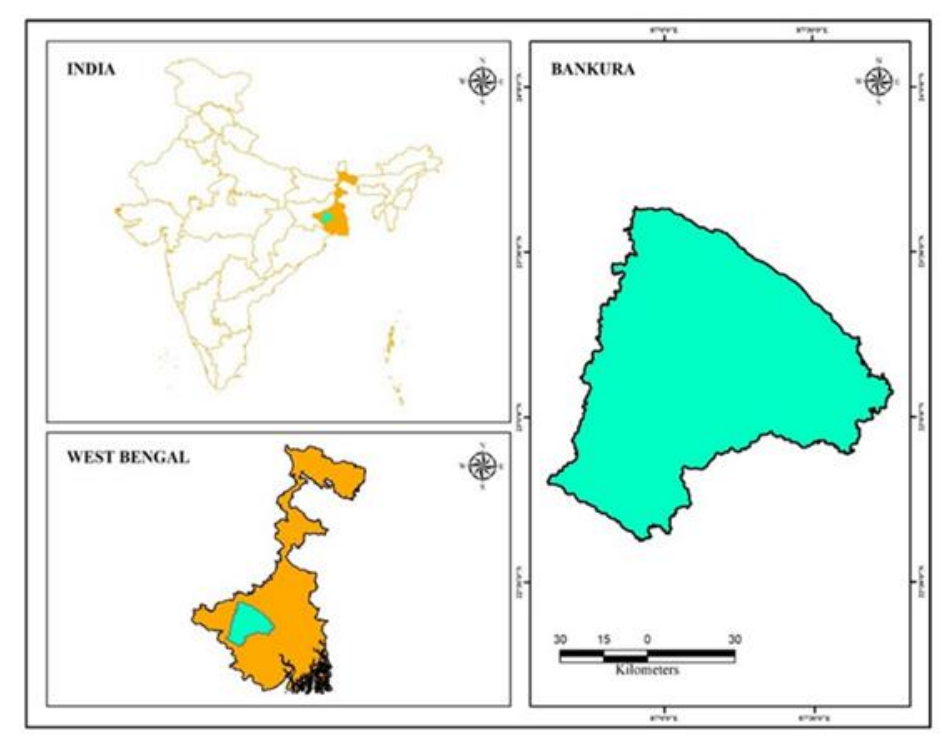

Figure 1. Study area location

The current study has been conveyed through a few stages to go before the decision-making approach. At first, relative accessibility index (RAI) has been assessed dependent on the current circumstance and accessible information on no. of the medical establishment, number of patients, number of doctors for example doctor- patient proportion. The RAI of medical care facilities is the sign of the areal extent of healthcare services which help in analyzing accessibility and inaccessibility. For the equivalent, Euclidean distance, kernel density and proximity had been examined to help suitability 
analysis of healthcare services utilizing the weighted linear combination. Parallelly, TOPSIS was applied to determine the most suitable sites where new hospitals could be worked to contact greatest individuals to give better healthcare services. At the end, the shortest path network analysis was estimated to associate and interlinked among existing district medical hospital and proposed healthcare. Figure 2 presents methodology flowchart.

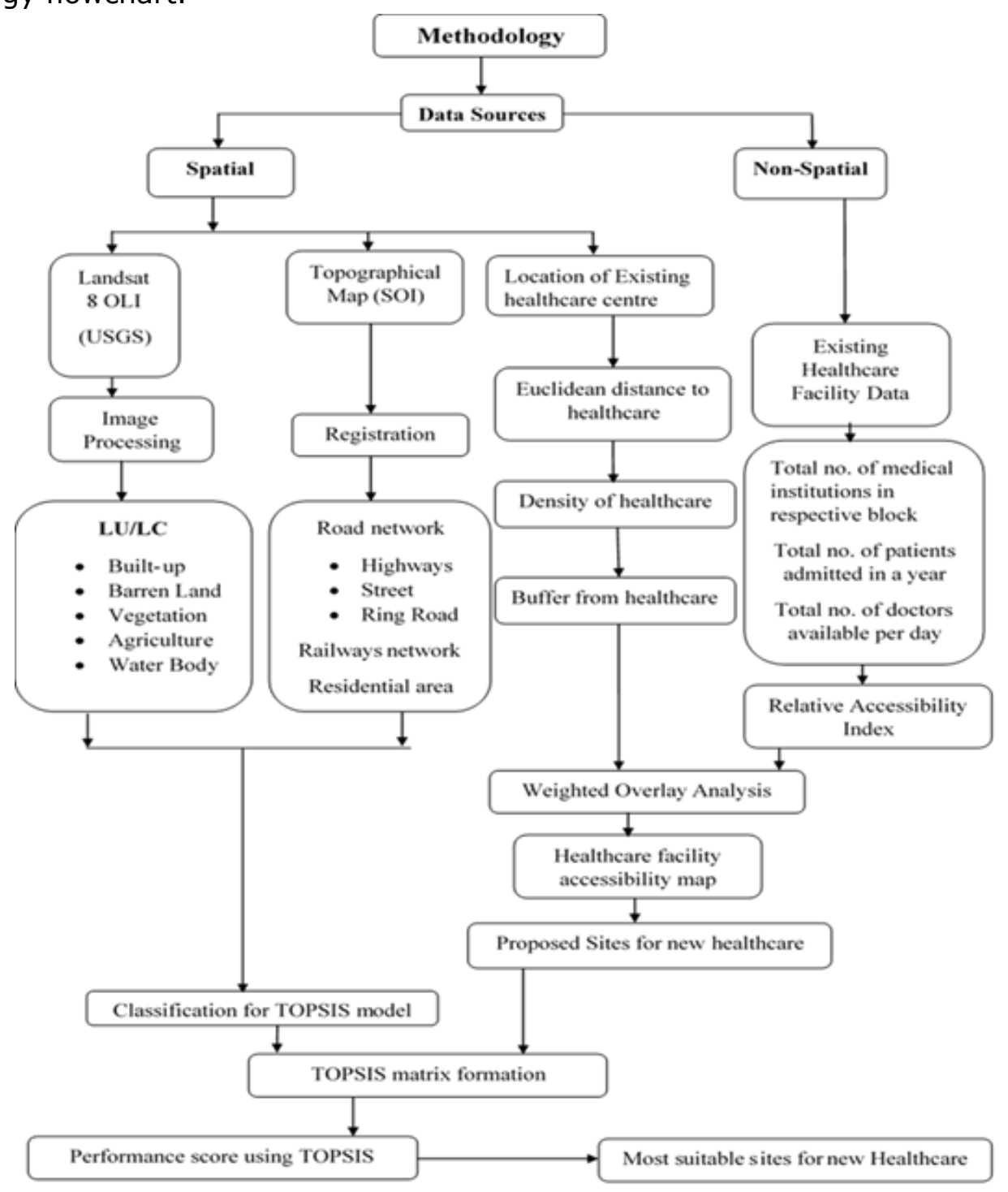

Figure 2. Methodology flowchart

\section{Results and discussion}

Bankura district is quite possibly the most immature areas in West Bengal. The space of the region is huge, and it is meagerly populated. This makes it very hard to make quality health administrations accessible to the local area. Customarily Bankura has been known for the issue of sickness, jungle fever and filaria. Then again, the level of unhealthiness and baby death rate have additionally been significant. For the current circumstance of health care offices, the relative accessibility index (RAI) was determined by thinking about no. of hospitals, no. of patients conceded in a year, and no. of specialists accessible each day.

The consequence of the current circumstance of health care services uncovers that the spatial circulation isn't uniform all through the locale (Figure 5.1). Consequently, for better treatment and getting great help, the occupant needs to travel somewhere else in 
the rise of intersection a significant distance, though, numerous reasonable conditions for growing better assistance have effectively existed here. The quantities of clinical organizations have grouped at the focal piece of the region i.e., the locale capital, Bankura-I. Thus, the inhabitants of different regions are endured to improve offices. In this way, the current examination was completed to discover appropriate areas for health care facilities by fostering a dynamic model. For the equivalent, the choice progression was created utilizing existing offices of health administration, their spatial distance, density, and proximity to help the reasonable spots; where better and all-around obliged health care administration would be proposed by considering the nearer to land use and distance to transportation course.

The existing total medical institution is not much as its population required. In this district no of medical institution is much lower and spatially unwell distributed. Bankura (The headquarter of the district) has higher, where Onda, Barjora, Chhatna, Taldngra has a moderate and Sonamukhi, Saltora, Joypur and respectively have much lower. So, these areas people must travel throughout the capital city of the district for healthcare services.

Figure 3 represents the overarching states of health care administrations including medical college, emergency health care and nursing home. There are just a single medical college and health care is accessible for the district. There are some different emergency clinics and nursing home likewise accessible both legislative and public however the spatial equity or homogeneity isn't found. Figure 5 show the distance, proximity, and density of healthcare offices individually.

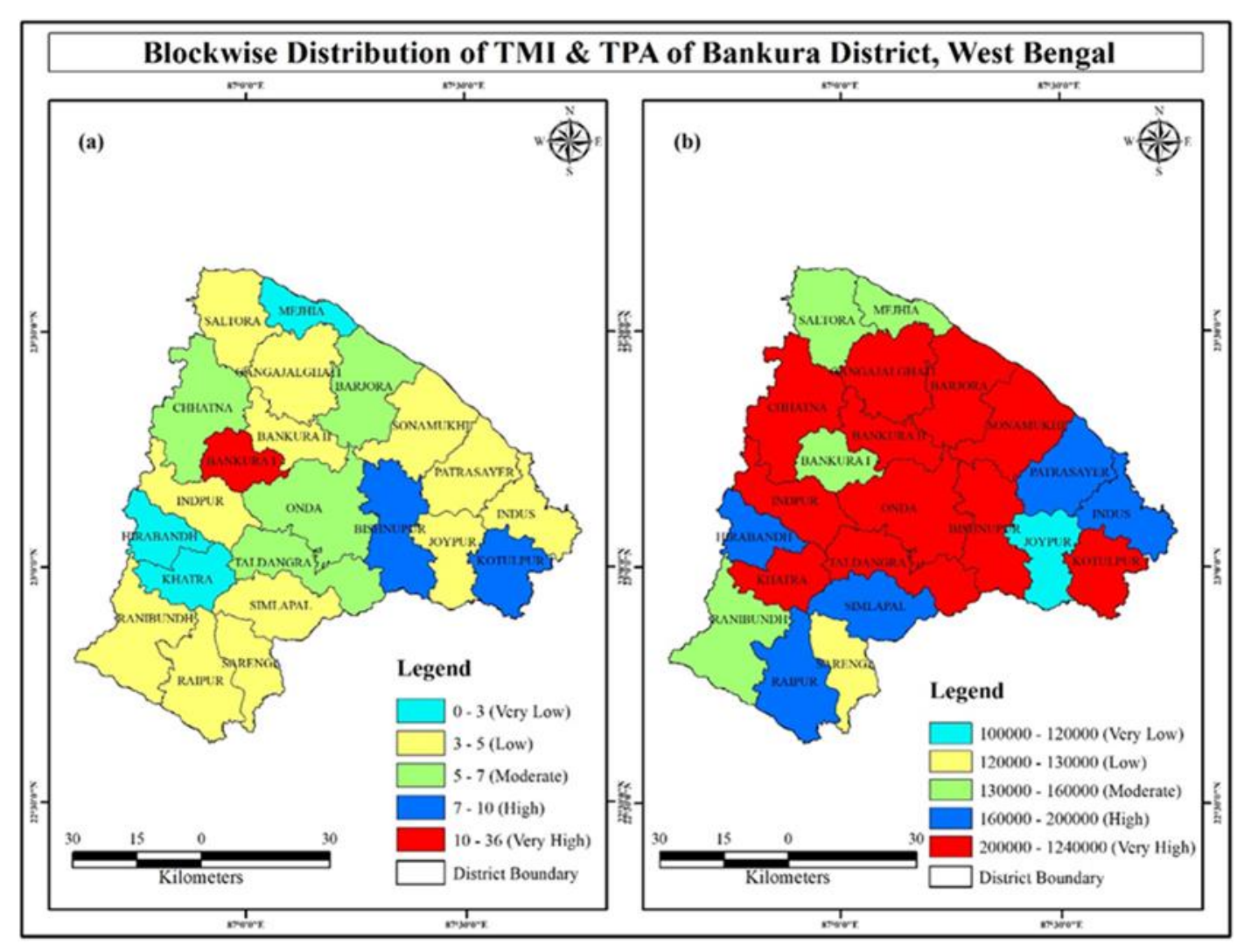

Figure 3. Total medical institution (a) and total patient allocated per block (b)

In terms of total patient allocated per block, Bankura-II, Sonamukhi, Chhatna, Kotlupur, Indpur, Onda, Gangajal Ghati, Khatra, Bishnupur, Taldongra and Barjora has the higest no of patient. Bankura-I, Ranibundh, Saltora and Mejhia bocks has a moderate no of patient and Joypur has the lowest number. After evaluating the no of medical 
institution and no of patient per block we observe that this district peoples are suffering for better healthcare services and there is a need of some healthcare facility especially government hospitals. Our study involves finding out the best site selection to fulfil the requirement of medical facility to the entire district.

The relative accessibility index (RAI) of present health care service was calculated and the result reveals that only Bankura-I (headquarter of the district) block has good RAI, whereas Bishnupur, Khatra and Kotulpur have moderate RAI and all others 20 blocks have low to very low RAI value. Subsequently, from the overall spatial outcome of the relative accessibility index, it can be concluded by assuming that the study area is poor in terms of healthcare services and health care facilities. Therefore, looking towards this problematic issue, the present study proposed a MCDA decision model with three phases of analysis to find suitable places for built new health care and shortest distance to interconnect with the district medical hospital. The first phase of analysis point up the distance, density and proximate of each existing health care to seek out a lot of underprivileged and inaccessible areas in the view of health services. The second phase of analysis make a point to seek out appropriate sites for proposing new health care services dependent on selected criteria (land use land cover, distance to road, rail, and proximity to residential areas). Finally, the third phase of analysis point out the foremost suitable sites between the proposed new health care and network analysis throughout the shortest path to link with district medical hospital. In terms of healthcare facility of Bankura, most of the medical institution are present in the middle part, like Bankura-I, Bankura-II, Barjora, Chatna and respective blocks. Middle part of the district has well distributed healthcare facilities and higher amount of people take the advantage of that (Figure 4). Buffer around healthcare created for selecting the sites, in a minimum distance from existing healthcare. Buffer around healthcare classified into five classes 5 to $25 \mathrm{~km}$. after considered the factor criteria and constrain criteria along with these layers' sites are selected.

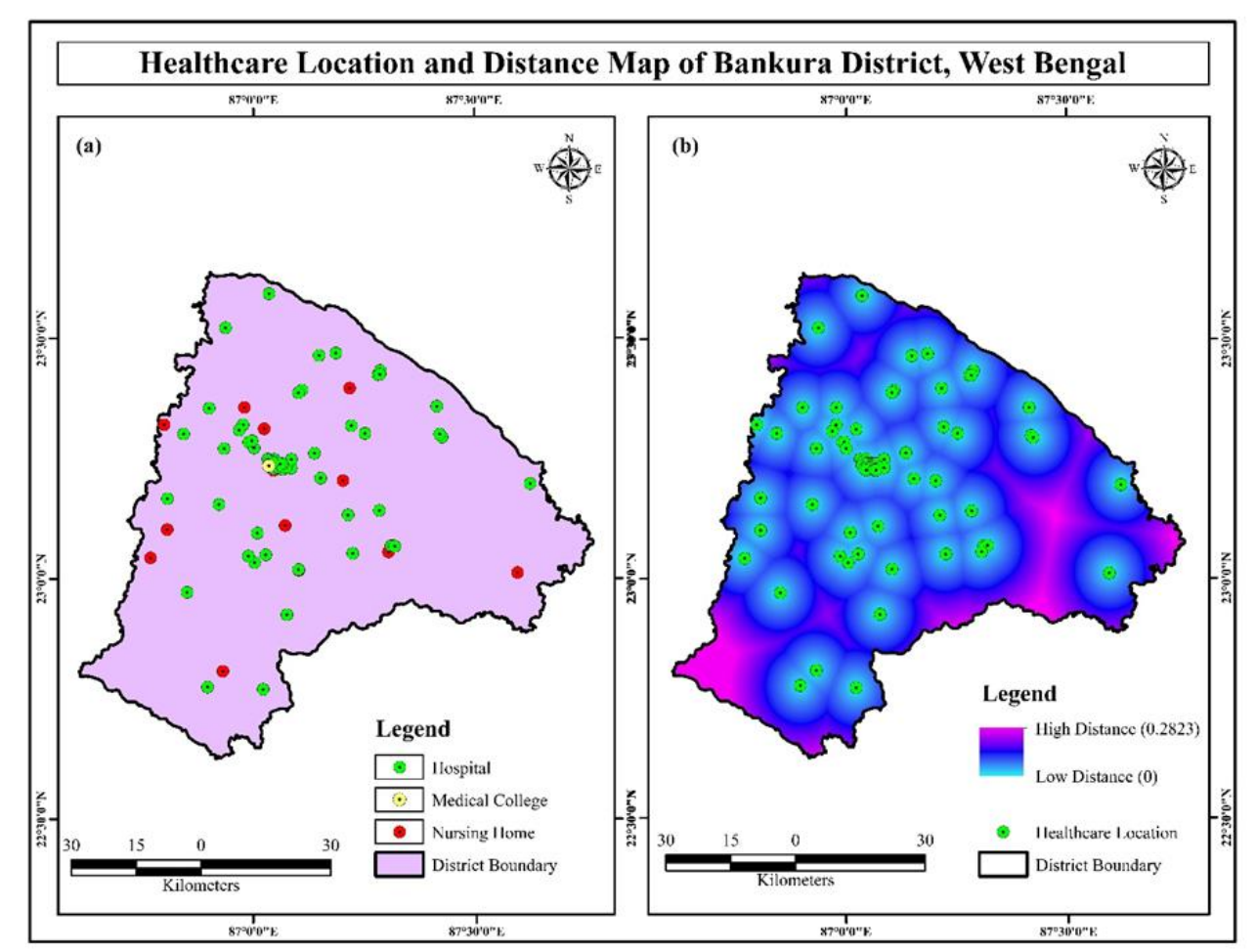

Figure 4. Existing healthcare locations (a) and distance map of healthcare (b) 
Figure 5 show the distance, thickness, and proximate to introduce healthcare services separately. The outcome from each layer of distance, thickness, and proximate uncover that the fringe portions of the locale have consistently lower services. The lower distance to healthcare demonstrates higher accessibility; lower thickness of healthcare shows lower accessibility and nearer to healthcare shows higher accessibility.

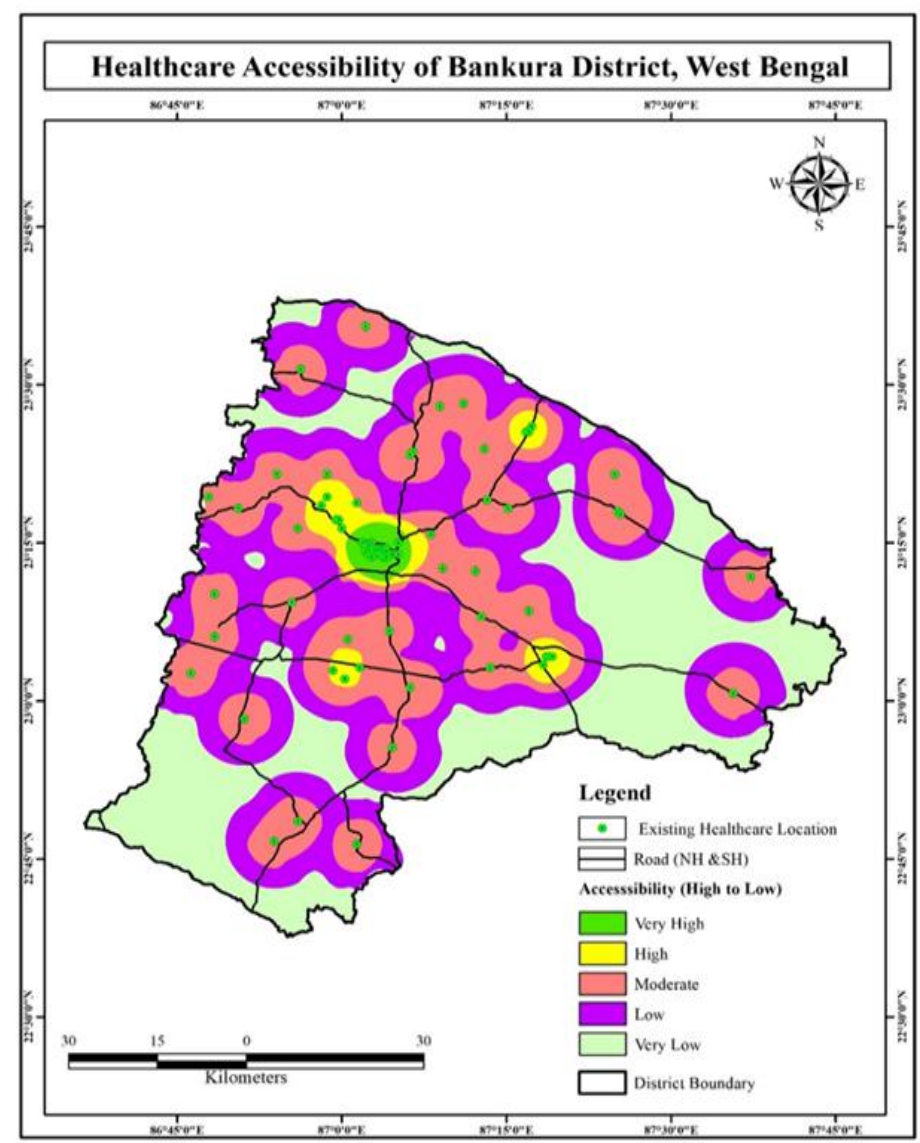

Figure 5. Weighted linear equal combination

Above three layers unified to take into consideration the accessibility and inaccessibility to healthcare services all over the current study area. The 1-to-5-point scale was employed for the linear combination i.e., one utilized to represent higher accessibility (inaccessibility) and five employed to indicate the lower accessibility of health care services. This result endorses the second phase of analysis i.e., to seek out suitable sites for proposing to build for a new healthcare service in inaccessible locations. Constraint criteria consists of several options. Ring road: there are some rings in the traffic system of Bankura. There is no need for new healthcare anymore inside the ring road where hospitals or clinics are already created. Highway: the land use around highway is usually open area. There is no need to have a healthcare there, from the view of economy and resource, both are waste. Railway: patently, patients will be disturbed by noisy sound when the train is passing by. Most of the railway stations are not nearer to the residential area, so hospital being built there is insignificant. Restaurant: hospital is the source of infection, to protect the public, keep a distance from the restaurants around is important. On the other hand, most hospitals in Bankura have their own canteen for patients. consequently, to build hospitals near restaurants on purpose is also meaningless. Greenbelt: hospitals are hardly ever built inside the greenbelt such as parks, it is recommended to protect those areas which are grown much green from the pollution of hospital. Reservoir: hospitals cannot be built around a reservoir; in case the 
reservoir is polluted by construction or drainage discharged by the hospital in the future. Altitude: most areas of Bankura District are in the flat region. While in the northwest of Bankura District, there are mountainous areas, which is not suitable for building a hospital. Proposed sites for new healthcare services are presented on Figure 6.

The proposed health care in a suitable site can be consolidated and interlinked with existing health care for upgrade and accessible of the region as far as health care facilities. It is essential to approve the space of each proposed site by checking the ground truth. In the current investigation, site- 1 and site- 6 were approved through the ground visit. However, the rest areas were not visited; taking everything into account, their ground truth was assessed in Google Earth Search Engine. All regions were picked in open space, barren land, or agricultural land, by considering their region nearer to settlement, closer to versatile courses.

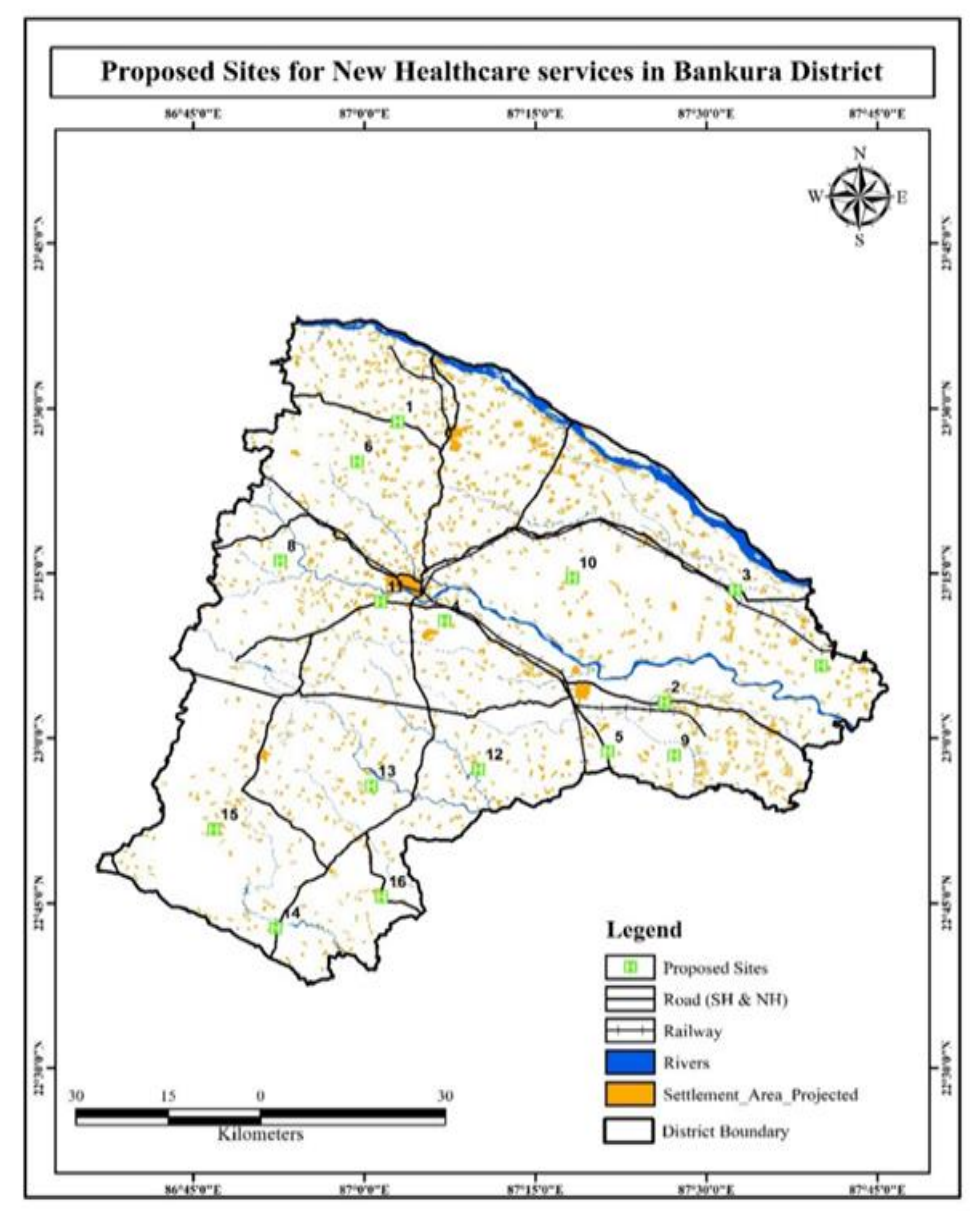

Figure 6. Proposed sites for new healthcare services

\section{Conclusions}

While numerous past scientists have featured the nonspatial information and measurable induction to dissect healthcare accessibility in a geological area, the current study applied a GIS-based multicriteria decision making approach for evaluating the spatial accessibility of healthcare services and site suitability analysis in Bankura district of West Bengal, India. This study offered a MCDA decision-making approach for proposing suitable sites with respect to quality healthcare services. To offer better support and arrive at a denied gathering of individuals, an unrealistic fantasy was arranged that needs for consistent dynamic and resolve existing issues. The outcome uncovers that spatial error exists if there should arise an occurrence of admittance to 
healthcare services. The area of existing healthcare essentially groups in the focal and northern parts. The distance, density and proximity analysis of these healthcare investigated the spatial blocked off regions. To accomplish equivalent access, allotment of new healthcare is fundamental to lessen the spatial uniqueness. Along these lines, the equal weight-based weighted linear combination was performed utilizing land use land cover, closeness to road and rail, and distance to residential areas to help suitable site for deciding and dispensing new healthcare sites. Decision support system with GIS integration offered 16 suitable sites in blocked off regions. Lower accessibility and chronic health care services in a space increment health and social variations. Thus, the critical prerequisite is expected to expand accessibility. The current study underscored similar issue and fostered a mixture way to deal with incorporate various factors to propose sites for new healthcare services and eliminate spatial difference in the study area. The benefits of creating and utilizing a MCDA model are (1) it incorporates various models and approach, (2) it expands the exactness of the outcome and decreases the disadvantages of single model and technique, (3) it interlinks at least two parts of a study, for example, if there should be an occurrence of the current study utilizing a MCDA model two angles, for example accessibility to healthcare and site suitability of healthcare have been resolved, and (4) MCDA model aides in improving on the unpredictable relationship of among rules or point of view. Be that as it may, a MCDA model likewise experiences a few hindrances, like (1) it is more intricate to apply (2) the preparedness of model take a greater number of times than single model (3) once in a while it additionally experiences overfitting and so on Hence, eliminating such inconveniences and embracing the previously mentioned benefits, the present proposed and utilized a MCDA model to show healthcare accessibility and site suitability. This examination would seem like a decent wellspring of health care facility upgrade and plan execution to policymakers and health organizers. As of late, our nation as well as the world stressed over the flare-up of 'novel Coronavirus'. The public authority really discovers tremendous space for 'isolation' service. Worldwide 172,293,942 affirmed cases are accounted for (till 05.06.2021). In the view of current scenario, India's situation is not well, it takes 2nd position after United Sates with 28,574,350 affirmed cases are distinguished. It is accepted that Bankura is likewise a lot of defenseless as there is an absence of fundamental foundation. Thusly, in such manner, it is suggested that Government and local organizers can begin health related crisis in proposed sites with essential gear and service to arrive at target populace gatherings. On getting accomplishment in the mission, current infrastructural improvement and services could be proposed subsequently.

\section{References}

1. Abdullahi, S., Mahmud, A. R. bin and Pradhan, B. (2014) 'Spatial modelling of site suitability assessment for hospitals using geographical information system-based multicriteria approach at Qazvin city, Iran', Geocarto International, 29(2), pp. 164-184. doi: https://doi.org/10.1080/10106049.2012.752531

2. Ahmad, M. B. et al. (2020) 'Geospatial assessment of physical accessibility of healthcare and agent-based modeling for system efficacy', GeoJournal, 85(3), pp. 665-680. doi: http://dx.doi.org/10.1007/s10708-019-09987-z.

3. Beheshtifar, S. and Alimoahmmadi, A. (2015) 'A multiobjective optimization approach for location-allocation of clinics', International Transactions in Operational Research, 22(2), pp. 313-328. doi: https://doi.org/10.1111/itor.12088.

4. Behzadian, M. et al. (2012) 'A state-of the-art survey of TOPSIS applications', Expert Systems with Applications, 39(17), pp. 13051-13069. doi: https://doi.org/10.1016/j.eswa.2012.05.056.

5. Case, C. and Hawthorne, T. L. (2013) 'Served or unserved? A site suitability analysis of social services in Atlanta, Georgia using Geographic Information Systems', Applied Geography, 38, pp. 96-106. doi: https://doi.org/10.1016/j.apgeog.2012.11.012.

6. Dutta, B. et al. (2021) 'Spatial analysis and modelling for primary healthcare site selection in 
Midnapore town, West Bengal', GeoJournal. doi: 10.1007/s10708-021-10528-w.

7. Jozaghi, A. et al. (2018) 'A Comparative Study of the AHP and TOPSIS Techniques for Dam Site Selection Using GIS: A Case Study of Sistan and Baluchestan Province, Iran', Geosciences . doi: $10.3390 /$ geosciences8120494.

8. Mishra, S. et al. (2019) 'Geo-spatial site suitability analysis for development of health care units in rural India: Effects on habitation accessibility, facility utilization and zonal equity in facility distribution', Journal of Transport Geography, 78, pp. 135-149. doi: https://doi.org/10.1016/j.jtrangeo.2019.05.017.

9. Nations, U. (2015) UN chief urges greater efforts to improve health and well-being of indigenous people, UN News Centre. Available at: https://www.un.org/en/development/desa/news/social/indigenous-peoples.html (Accessed: 23 July 2021).

10. Nghiem, S. H. and Connelly, L. B. (2017) 'Convergence and determinants of health expenditures in OECD countries', Health Economics Review, 7(1), p. 29. doi: 10.1186/s13561-017-0164-4.

11. Nyimbili, P. H., Erden, T. and Karaman, H. (2018) 'Integration of GIS, AHP and TOPSIS for earthquake hazard analysis', Natural Hazards, 92(3), pp. 1523-1546. doi: 10.1007/s11069-018-3262-7.

12. Ozturk, D. and Batuk, F. (2011) 'TECHNIQUE FOR ORDER PREFERENCE BY SIMILARITY TO IDEAL SOLUTION ( TOPSIS ) FOR SPATIAL DECISION PROBLEMS', in.

13. Pan, X. et al. (2018) 'Evaluating the Accessibility of Healthcare Facilities Using an Integrated Catchment Area Approach', International Journal of Environmental Research and Public Health . doi: 10.3390/ijerph15092051.

14. Parvin, F. et al. (2021) 'Accessibility and site suitability for healthcare services using GIS-based hybrid decision-making approach: a study in Murshidabad, India', Spatial Information Research, 29(1), pp. 1-18. doi: 10.1007/s41324-020-00330-0.

15. Pu, Q. et al. (2020) 'Improving the spatial accessibility of healthcare in North Kivu, Democratic Republic of Congo', Applied Geography, 121, p. 102262. doi: https://doi.org/10.1016/j.apgeog.2020.102262.

16. Rekha, R. S. et al. (2017) 'Accessibility Analysis of Health care facility using Geospatial Techniques', Transportation Research Procedia, 27, pp. 1163-1170. doi: https://doi.org/10.1016/j.trpro.2017.12.078.

17. Stylianidis, E., Roustanis, T. and Karanikolas, N. (2009) 'A Geographical Information System for Real Estate (GEOVAL) BT - Location Based Services and TeleCartography II: From Sensor Fusion to Context Models', in Gartner, G. and Rehrl, K. (eds). Berlin, Heidelberg: Springer Berlin Heidelberg, pp. 317-329. doi: 10.1007/978-3-540-87393-8_19.

18. Zhao, Y. et al. (2018) 'Towards Sustainable Urban Communities: A Composite Spatial Accessibility Assessment for Residential Suitability Based on Network Big Data', Sustainability . doi: 10.3390/su10124767.

19. Zhou, L. and Wu, J. (2012) GIS-Based Multi-Criteria Analysis for Hospital Site Selection in Haidian District of Beijing. Faculty of Engineering and sustainable development. Available at: https://www.diva-portal.org/smash/get/diva2:555935/FULLTEXT01.pdf. 